\title{
Multimedia Environment and Gender, in Motor-Rhythmic Performance of a Dance Routine with Ball, Accompanied by an Adjusted Music Composition
}

\author{
Barbara Pateraki
}

University of Thessaly, Department of Physical Education and Sport Science, Trikala, Greece, E-mail: pateraki@pe.uh.gr

Elisana Pollatou (Corresponding author)

University of Thessaly, Department of Physical Education and Sport Science, Trikala, Greece, E-mail: epolatou@pe.uth.gr

Marina Papastergiou

University of Thessaly, Department of Physical Education and Sport Science, Trikala, Greece, E-mail: mpapas@pe.uth.gr

Konstantina Karadimou

University of Thessaly, Department of Physical Education and Sport Science, Trikala, Greece, E-mail: ckaradim@pe.uth.gr

Received: September 24, 2013 Accepted: October 8, 2013 Published: October 10, 2013 doi:10.5296/jet.v1i1.4403 URL: http://dx.doi.org/10.5296/jet.v1i1.4403 


\section{Abstract}

The principal objective of this study is the effect of using of an online-multimedia environment and that of gender on learning and performing a motor-rhythmic routine with a ball followed by a customized music composition towards students of DPESS. Seventy six (76) sophomore students took place in the examination (43 men and 33 women), randomly divided into two groups consisting of an equal number of students. The examinees attended university courses of rhythmic gymnastics regarding the routine with the ball, for four weeks. Along with the physical practice of the routine in the classroom, the experimental group could make use of an online-multimedia environment, which consisted of videos, images and audio of the routine for extra feedback, whereas the control group could only practice physically. The routine contained 31 main body movements (swings, turns, balances, jumps, etc.) along with handling a ball (rolls, throws, bounces, etc.). Each student attempted performing the motor-rhythmic routine with music both at the beginning and the end of the interventions. Every performance was videotaped so as to evaluate each individual movement and rhythmic skill. According to the results of the final evaluation both groups improved significantly, compared to the first performance both in movement and rhythm. In more detail, the paired-samples t-tests showed that there was a significant difference between the pre-test and post-test in the motor and rhythmic performance. In addition, the results of the independent-samples t-tests showed that the difference in the improvement of the motor and rhythmic performance was not significantly important towards the group and gender. To sum up, the students advance in their performance of the motor-rhythmic routine with a ball, in movement and rhythm, having had no significant effect from the use of an online-multimedia environment or from their gender. Thus the physical practice alone seems to be equally effective towards the improvement of the motor and rhythmic performance. Furthermore, the rhythmic performance of the students seemed to lack improvement compared to the motor performance, according to the results. Therefore, there may be a possibility that teaching basic motor skills is more effective by inducting the motor component first and then adding the rhythmic elements. Such a teaching process could impact future research.

Keywords: motor \& rhythmic performance, multimedia environment, dance routine with ball

\section{Introduction}

Nowadays, it is vital for a person to have the opportunity towards multiple ways of education, having options depending on one's different difficulties such as location, time, financial situation and also one's personality (Kotsilieris, Cotsakis, Loumos, \& Kayafas, 2003). According to Mayer (1996), one has visual and auditory capabilities for processing information, and so with the use of multimedia both of these capabilities are exploited simultaneously. Some summarized relevant research studies include:

A study involving the development of an online multimedia environment for teaching traditional Greek dancing has shown that with the appropriate multimedia tools, attractive and functional dance resources can be created for the web, which may support the education of traditional Greek dancing towards new students (Karkou, Bakogianni \& Kavakli, 2008). Another research study involved the evaluation of learning the rules of golf (Adams, Kandt, 
Throgmartin, \& Waldrop, 1991), which were taught to novice university students using two methods: a) computer - assisted instruction and b) lecture methods. The results showed no differences between the groups. McKethan and Everhart (2001) also evaluated the effect of multimedia software, but on teaching the theory cues of manipulate skills on pre-service physical education. The study involved undergraduate students classified into three groups: a) traditional taught, b) multimedia taught and c) control group. The multimedia taught group and the traditional taught group improved in all skills with no significant differences.

Signifying that applying selected music can have a positive effect on the technique of movement in sports (Chen, 1985; Spilthoorn, 1986), the motor - music education is thought to be useful during physical activities. Karageorghis and Priest (2008) found that music may serve as an incentive towards increasing participation, exercise intensity and endurance in physical activity, in one of their research studies. The present study aims at improving the technique of basic gymnastic skills, using a complex motor - rhythmic routine, with customized music composition. An issue is the impact that an additional multimedia learning environment may have compared to the traditional teaching method in class.

While observing a model performing a dance routine correctly on video, one has the ability to imagine oneself doing the movement before acting on it. Moreover, although it is proven that mental exercise may improve one's skills further, it is worth mentioning that it is not as effective if the students haven't practiced the movement or have low leveled motor skills (Wilmerding \& Krasnow, 2009).

To sum up, the learning process of a dance routine consists of observation, practice, feedback and it can be provided by different teaching methods, according to the different needs of each individual student. Aiming towards an effective teaching method for a motor-rhythmic routine, could the use of multimedia during the learning progress improve the performance of motor skills to the corresponding pace of music, and which is the impact of gender on this process?

\section{Method}

\subsection{Examinees}

Seventy six (76) sophomore students of D.P.E.S.S. (University of Thessaly), 43 male and 33 female, took part in this study. Mean student age was 20.18 years $(\mathrm{SD}=2.90)$. They were tested during their University course: "Rhythmic Gymnastics Education". Within the framework of the course, the students had already done four classes of rhythmic gymnastics, involving basic concepts of rhythm and basic movement skills, without being taught motor skills with a ball. The students did not have any prior knowledge or experience regarding the subject matter of the course addressed in the study.

\subsection{Process Measurement Data}

The examinees were randomly classified into two groups: a) online-multimedia taught (OMT) (38 people) and b) traditional taught (TT) (38 people). Then, both teams practiced the motor-rhythmic routine with the difference that the OMT group had access to an online 
multimedia learning environment at the same time. The online-multimedia learning environment included classes on each motor skill of the routine. It included explanation texts, images, videos and knowledge quizzes (www.pe.uth.gr/moodle/). At the pre-test the examinees watched the dance routine on video twice, executed by a man and then a woman. Then, they attempted executing the routine in groups of three, accompanied by the music composition. In the post-test, the participants watched the routine on video twice again and attempted executing it. All the attempts in both measurements were videotaped.

\subsection{The Teaching Program}

Both groups attended a teaching program which involved learning a motor-rhythmic routine with a ball. The course took place once a week for four weeks and lasted 90 minutes (2 teaching hours) each time. In each class, the students were taught in detail the contents of the routine. The movements were presented and explained by the teachers and then they were practiced by the students many times. The OMT group was also able to observe and study the routine online, reading the detailed description of the movements and watching the routine on video.

\subsection{The Content of the Teaching Program.}

The routine consisted of basic motor skills (jumps, balances, swings, turns, direction changes) and the use of a ball. The music composition was based on the rhythmic values corresponding to each move. It comprehended 8 musical rhythmic meters.

\subsection{The Evaluation}

Both the motor skills and the rhythm skills in the routine were evaluated by observing each participant in the videos of the pre-test and post-test. While closely observing the videos, every movement was analyzed and evaluated " 0 " for "no execution of the movement", " 1 " for "incorrect execution" and " 2 " for "correct execution". The number of movements that where correct, incorrect or not executed was indicated (see Table 1) and so any specific movements that where found hard or easy for the participants could also be identified. In a similar manner, the rhythmic skills where evaluated, scoring " 0 " if the participant executed the movement to the incorrect rhythmic value of the accompanied music or " 2 " if the rhythmic execution was correct. Knowing both the participants' total score of movement and rhythm in both post-test and pre-test, the improvement of each student could be calculated by the difference of the total score in each test (Post-test - Pre-test) (see Figures 1 and 2).

\section{Statistical Analysis}

For analyzing the results the SPSS program was used, as well as the Excel of Microsoft. It should be noted that the results presented in this paper constitute the outcomes of further analyses of a part of the research data collected in Papastergiou, Pollatou, Theofylaktou, and Karadimou (2013). 
Table 1. Aggregated comparative table between movement and rhythm (Final Evaluation). Not all movements are included, just the ones that correspond exactly to the rhythmic values of the routine

\begin{tabular}{|c|c|c|c|c|c|c|}
\hline \multirow[t]{2}{*}{ Movement } & \multirow[t]{2}{*}{$\begin{array}{l}\text { Rhythm } \\
\text { (rhythmic values) }\end{array}$} & \multicolumn{2}{|c|}{ No execution $(f)$} & \multirow{2}{*}{$\begin{array}{l}\text { Incorrect } \\
\text { Execution }(f) \\
\text { kinetic }\end{array}$} & \multicolumn{2}{|c|}{$\begin{array}{l}\text { Correct Execution } \\
\text { (f) }\end{array}$} \\
\hline & & kinetic & rhythmic & & kinetic & rhythmic \\
\hline $\begin{array}{l}\text { Swing arm } \\
\text { back }\end{array}$ & 3/8-triplet & 0 & 6 & 1 & 75 & 70 \\
\hline $\begin{array}{l}\text { Transfer the } \\
\text { ball }\end{array}$ & $1 / 4$ & 0 & 5 & 1 & 75 & 71 \\
\hline $\begin{array}{l}\text { Swing arm } \\
\text { back }\end{array}$ & 3/8-triplet & 0 & 7 & 1 & 75 & 69 \\
\hline $\begin{array}{l}\text { Transfer the } \\
\text { ball }\end{array}$ & $1 / 4$ & 0 & 7 & 3 & 73 & 69 \\
\hline Hold the ball & $1 / 4$ & 0 & 6 & 3 & 73 & 70 \\
\hline Roll the ball & $4 / 16$ & 0 & 13 & 4 & 72 & 63 \\
\hline $\begin{array}{l}\text { Throw the } \\
\text { ball }\end{array}$ & $1 / 4$ & 2 & 18 & 24 & 50 & 58 \\
\hline Catch the ball & $1 / 4$ & 13 & 23 & 13 & 50 & 53 \\
\hline $\begin{array}{l}\text { Pass the ball } \\
1\end{array}$ & $1 / 4$ & 4 & 22 & 7 & 65 & 54 \\
\hline $\begin{array}{l}\text { Pass the ball } \\
2\end{array}$ & $1 / 4$ & 3 & 17 & 7 & 66 & 59 \\
\hline $\begin{array}{l}\text { Pass the ball } \\
3\end{array}$ & $1 / 4$ & 7 & 15 & 6 & 63 & 61 \\
\hline $\begin{array}{l}\text { Pass the ball } \\
4\end{array}$ & $1 / 4$ & 10 & 20 & 5 & 61 & 56 \\
\hline Dribbling 1 & $2 / 8$ & 0 & 21 & 2 & 74 & 55 \\
\hline
\end{tabular}




\begin{tabular}{|c|c|c|c|c|c|c|}
\hline Dribbling 2 & $2 / 8$ & 2 & 19 & 13 & 61 & 57 \\
\hline Dribbling 3 & $2 / 8$ & 0 & 15 & 3 & 73 & 61 \\
\hline Dribbling 4 & $2 / 8$ & 2 & 29 & 30 & 44 & 47 \\
\hline Swing back & $3 / 8$ & 10 & 28 & 16 & 50 & 48 \\
\hline $\begin{array}{l}\text { Throw the } \\
\text { ball }\end{array}$ & $1 / 4$ & 5 & 24 & 6 & 65 & 52 \\
\hline $\begin{array}{l}\text { Bounce the } \\
\text { ball }\end{array}$ & $1 / 4$ & 4 & 21 & 9 & 63 & 55 \\
\hline Catch the ball & $1 / 4$ & 3 & 19 & 12 & 61 & 57 \\
\hline Balance & $2 / 4$ & 2 & 23 & 37 & 37 & 53 \\
\hline $\begin{array}{l}\text { Bounce the } \\
\text { ball }\end{array}$ & $1 / 4$ & 3 & 59 & 5 & 68 & 17 \\
\hline Catch the ball & $1 / 4$ & 4 & 43 & 4 & 68 & 33 \\
\hline "Pas de chat" & $\begin{array}{l}1 / 8 \text { dotted \& } \\
1 / 16\end{array}$ & 4 & 42 & 21 & 51 & 34 \\
\hline Step & $1 / 4$ & 5 & 37 & 21 & 50 & 39 \\
\hline Kneeling & $1 / 4$ & 4 & 28 & 2 & 70 & 48 \\
\hline $\begin{array}{l}\text { Transfer the } \\
\text { ball }\end{array}$ & $1 / 4$ & 8 & 33 & 11 & 57 & 43 \\
\hline Roll the ball & $4 / 16$ & 4 & 33 & 28 & 44 & 43 \\
\hline Turn & $2 / 8$ & 6 & 36 & 32 & 38 & 40 \\
\hline $\begin{array}{l}\text { Transfer the } \\
\text { ball }\end{array}$ & $1 / 8$ & 8 & 38 & 36 & 32 & 48 \\
\hline $\begin{array}{l}\text { Stabilize the } \\
\text { pose }\end{array}$ & $1 / 4$ & 8 & 31 & 39 & 29 & 45 \\
\hline
\end{tabular}




\section{Results}

The results of the paired-samples t-tests proved that there was a significant improvement in motor performance from pre-test $(\mathrm{M}=25.51, \mathrm{SD}=10.33)$ to post-test $[\mathrm{M}=85.67, \mathrm{SD}=11.36$; $\mathrm{t}(75)=-37.883, \mathrm{p}<0.001]$, and also a significant improvement in execution rate from pre-test $(\mathrm{M}=3.76, \mathrm{SD}=5.35)$ to post-test [42.58, $\mathrm{SD}=15.18 ; \mathrm{t}(75)=-21.118, \mathrm{p}<0.001]$. The results of the independent samples t-tests showed that the improvement in the motor performance was not significantly different between the OMT group $(\mathrm{M}=62.68, \mathrm{SD}=11.76)$ and the TT group $[\mathrm{M}=57.63, \mathrm{SD}=15.40 ; \mathrm{t}(74)=1.608, \mathrm{p}=0.112]$ nor between male $(\mathrm{M}=57.91, \mathrm{SD}=13.53)$ and female $[\mathrm{M}=63.09, \mathrm{SD}=13.90 ; \mathrm{t}(74)=-1.636, \mathrm{p}=0.106]$ students. The results of the independent samples t-tests showed that the improvement in rhythmic performance was also not significantly different between the OMT group $(\mathrm{M}=37.84, \mathrm{SD}=15.04)$ and the TT group $[\mathrm{M}=39.79, \mathrm{SD}=17.10 ; \mathrm{t}(74)=-0.527, \mathrm{p}=0.6]$ nor between male $(\mathrm{M}=36.19, \mathrm{SD}=17.41)$ and female $[\mathrm{M}=42.24, \mathrm{SD}=13.51 ; \mathrm{t}(74)=-1.652, \mathrm{p}=0.103]$ students.

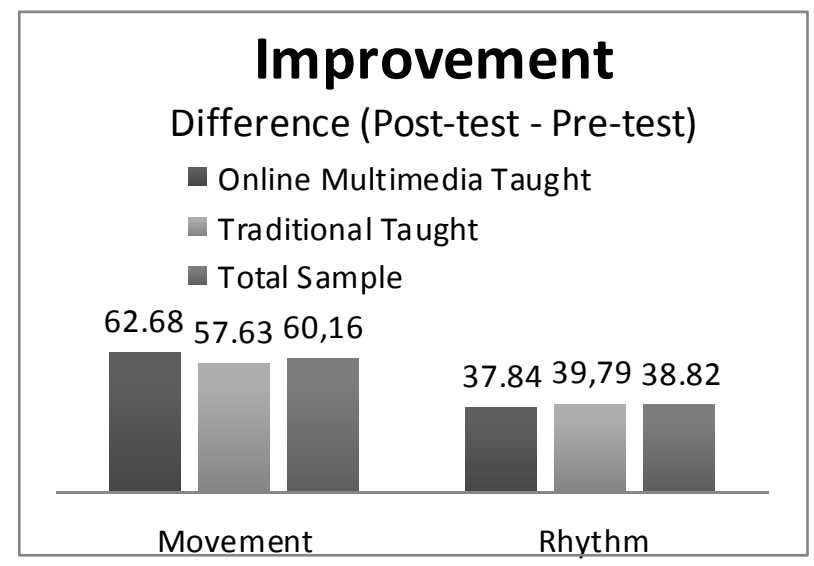

Figure 1. Improvement of groups in the execution of movement and rhythm

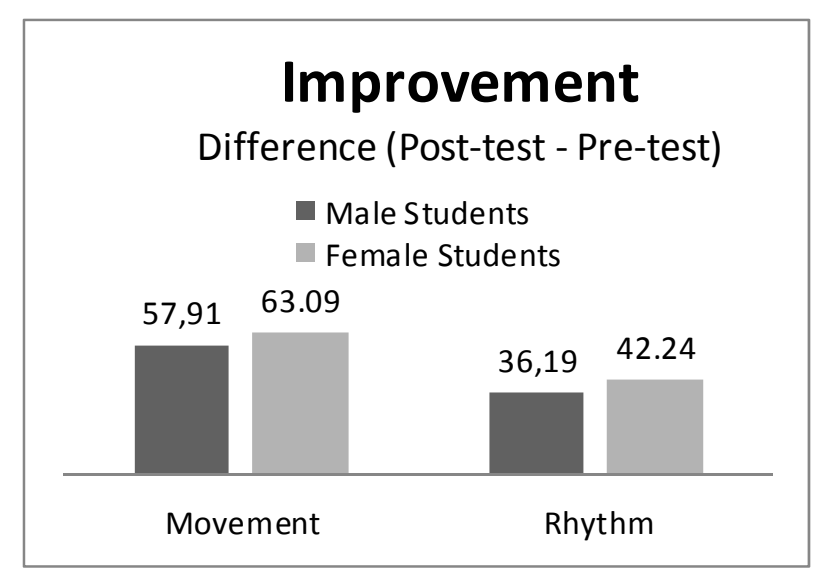

Figure 2. Improvement of genders in the execution of movement and rhythm

\section{Conclusion}

The study proved that there is no significant difference, in motor-rhythmic skill development, between students of D.P.E.S.S. who use a multimedia environment and students who were taught just with the traditional method nor between male and female students. Nevertheless, however, there is a significant overall improvement. Another research on using multimedia technology in learning and teaching traditional Greek dancing (Tsiatsos, Stavridou, Grammatikopoulou, \& Douka, 2010) had similar results. Tsiatsos and his partners showed that the use of annotated dance videos is effective towards experienced dancers and just neutral for beginners. The use of such educational dance videos does not seem to be effective towards beginners due to the fact that their experience level is not high enough for learning such motor skills. That could mean, the participants need more physical practice than mental, so that they internalize the motor patterns that are required for the dance routine. What also needs to be noticed is that traditional Greek dancing is known to usually exclude complicated 
kinetic patterns (focusing mostly on kinetic feet patterns) in contrast with the requirements of the routine in the present study. Nonetheless, repetition and regular practice of the dance movements are necessary (Wilmerding \& Krasnow, 2009) for improvement. If the movements have been repeated in the past several times, even in different order, the student will have enough experience, so as to execute the dance routine, without thinking of both the order of the movements and the technique. The approach presented in this paper offers a variety of motor skills, combined with the use of a gymnastic item and accompanied custom music composition, elements which could classify it as original research work. To conclude, the results suggest that for such motor skills, the practitioners should first understand the basic movements of the routine, so they can execute them easily, and then combine them to the corresponding rhythmic/music composition.

\section{Acknowledgement}

A brief version of this paper, in Greek, was presented in a conference (Pateraki, Pollatou, Papastergiou, \& Karadimou, 2013).

\section{References}

Adams, T., Kandt, G., Throgmartin, D., \& Waldrop, P. (1991). Computer - assisted instruction vs lecture methods in teaching the rules of golf. Physical Educator, 48, 146-150.

Chen, P. (1985). Music as a stimulus in teaching motor skills. New Zealand Journal of Health, Physical Education and Recreation, 18, 19-20.

Karageorghis, C. I., \& Priest, D. L. (2008). Music in sport and exercise: An update on research and application. The Sport Journal, 11. Retrieved from http://www/thesportjournal.org/article/music-sport-and-exercise-update-research-and-applicat ion

Karkou, V., Bakogianni, S., \& Kavakli E. (2008). Traditional dance, pedagogy and technology: an overview of the WebDANCE project. Research on Dance Education, 9(2), 163-186. http://dx.doi.org/10.1080/14647890802087985

Kotsilieris, T., Cotsakis, S., Loumos, V., \& Kayafas W. (2003). An open e-learning framework within a high availability network infrastructure. International Conference Automatics and Informatics, 1, 25-28.

Mayer, R. E., Bove, R., Bryman, W., Mars, A., \& Tapangco, L. (1996). When less is more: meaningful learning from visual and verbal summaries of Science textbook lesson. Journal of Educational Psychology, 88, 64-73. http://dx.doi.org/10.1037/0022-0663.88.1.64

Mckethan, R., \& Everhart, B. (2001). The effects of multimedia software instruction and lecture based instruction on learning and teaching cues of manipulate skills on preservice physical education teachers. Physical Educator, 58(1), 2-14.

Papastergiou, M., Pollatou, E., Theofylaktou, I., \& Karadimou K. (2013). Examining the potential of web-based multimedia to support complex fine motor skill learning: An empirical study. Education and Information Technologies. 
http://dx.doi.org/10.1007/s10639-013-9256-x

Pateraki, V., Pollatou, E., Papastergiou, M., \& Karadimou, K. (2013). The effect of a multimedia environment towards the motor-rhythmic performance of a dance routine with a ball accompanied by an adjusted music composition, by students of D.P.E.S.S. Short Papers of the $21^{\text {st }}$ International Congress of Physical Education \& Sport, Komotini, 17-19 May 2013 (pp. 27-31) (in Greek).

Schmidt, R. (1993). Consciousness, learning and interlanguage pragmatics. In G. Kasper \& S. Blum-Kulka (Eds.), Interlanguage Pragmatics (pp. 21-42). Oxford: Oxford University Press.

Spilthoorn, D. (1986). The effect of music on motor learning. Bulletin de la Federation Internationale de l'Education Physique, 56, 21-29.

Tsiatsos, T., Stavridou, E., Grammatikopoulou, A., \& Douka, S. (2010). Exploiting annotated video to support dance education. Proceedings of the 2010 Sixth Advanced International Conference on Telecommunications (AICT), Barcelona, 9-15 May 2010 (pp. 100-105), http://dx.doi.org/10.1109/AICT.2010.59

Wilmerding, V. \& Krasnow, D. (2009). Motor Learning and Teaching Dance. IADMS Retrieved from http://www.iadms.org/displaycommon.cfm?an=1\&subarticlenbr=250

\section{Copyright Disclaimer}

Copyright reserved by the author(s).

This article is an open-access article distributed under the terms and conditions of the Creative Commons Attribution license (http://creativecommons.org/licenses/by/3.0/). 